\title{
Scanning electron microscopy of granuloma annulare*
}

\author{
Hiram Larangeira de Almeida Jr. ${ }^{1,2}$, Eduardo de Barros Coelho Bicca ${ }^{3}$, Mariani Magnus de Andrade ${ }^{4}$, \\ Pedro da Rocha Andrade Neto ${ }^{4}$
}

DOI: http:/ / dx.doi.org/10.1590/abd1806-4841.20187409

\begin{abstract}
Light microscopy of granuloma annulare shows mucin deposition with lympho-histiocytic infiltrate. We describe the ultrastructural three-dimensional aspects of a typical case of granuloma with characteristic histopathological findings. At the ultrastructural level, affected collagen bundles and granular mucin deposition were observed. Round cells corresponding to lymphocytes were identified. Bigger oval cells, corresponding to isolated or palisading histiocytes were also found. The ultrastructural aspects overlap with light microscopy and contribute to its iconographic documentation.
\end{abstract}

Keywords: Histiocytes; Microscopy, electron, scanning; Mucins

\section{INTRODUCTION}

Granuloma annulare (GA) is a well-known disease that was first described in 1895 by Thomas Colcott Fox. Henry Radcliffe Crocker, in 1902, coined the term granuloma annulare. It is a relatively common and benign lesion of unknown cause and consists of a granulomatous dermatitis, characterized by grouped papules in an enlarging annular shape. The disorder can affect people of any age or ethnicity. However, $66 \%$ of the patients are under 30 years of age, and it occurs more often in females than males. ${ }^{1,2}$

Localized GA occurs more often than the other forms, i.e., generalized or disseminated, perforating, and subcutaneous. ${ }^{2-4}$ The localized form of granuloma annulare corresponds to $75 \%$ of cases. It starts with a small ring of firm red or pink papules. As the condition progresses, there is some central involution, and then the ring slowly grows in diameter. The condition resolves within one to two years in $50 \%$ of the cases. ${ }^{5}$
Light microscopy of GA shows focal degeneration of collagen, with surrounding areas of reactive inflammation and fibrosis. ${ }^{2-5}$ The epidermis appears normal, except in the perforating variant. The pattern of collagen degeneration is a spectrum that varies from large foci of full degeneration, with surrounding palisaded histiocytes and central mucin, to small foci of incomplete collagen degeneration. An infiltration of lymphocytes, histiocytes and fibroblasts is found between the normal and partially degenerated collagen. ${ }^{6-8}$

We report a case of typical GA, which was biopsied for diagnosis confirmation (Figure 1). A small fragment of the dermis was separated for electron microscopy, fixed in glutaraldehyde, dehydrated, dried, metalized and examined with scanning electron microscopy (SEM). Light microscopy confirmed the clinical diagnosis, with granulomatous formation and dermal basophilic deposits associated with lymphohistiocytic infiltrate and some giant cells (Figure 2).

Received 10 July 2017.

Accepted 20 October 2017.

* Work conducted in the Postgraduate Program of Health and Behavior, Universidade Católica de Pelotas, Pelotas (RS), Brasil; Dermatology League, Universidade Federal de Pelotas, Pelotas (RS), Brasil.

Financial support: None.

Conflict of interest: None.

Department of Dermatology, Universidade Federal de Pelotas, Pelotas (RS), Brazil.

Department of Dermatology, Universidade Católica de Pelotas, Pelotas (RS), Brazil.

Discipline of Pathology, Universidade Católica de Pelotas, Pelotas (RS), Brazil.

Medical student, Dermatology League, Universidade Federal de Pelotas, Pelotas (RS), Brazil.

Mailing AdDress:

Hiram Larangeira de Almeida Jr

E-mail: hiramalmeidajr@hotmail.com

()2018 by Anais Brasileiros de Dermatologia 


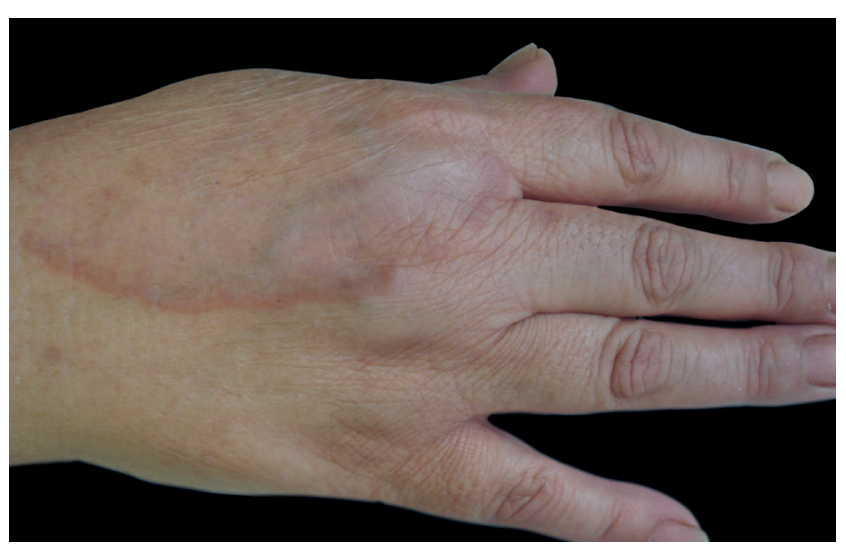

FigURE 1: Clinical aspect with typical annular lesion

\section{RESULTS}

Ultrastructural examination demonstrated normal collagen fibers arranged in parallel distribution, forming bundles (Figure $3 \mathrm{~A})$. In some examined fields, adjacent to the normal collagen, granular deposits corresponding to mucin deposition were observed amid irregular collagen that lacked bundle formation (Figure 3B and 3 C). Some round cells corresponding to lymphocytes were seen (Figure 3D). Some fields showed important collagen compaction (Figure 4A), where individual collagen fibers/bundles were no longer identified. Large oval-shaped cells corresponding to histiocytes were found alone (Figure 4B), forming palisade arrangements (Figure $4 \mathrm{C}$ ), or even in groups (Figure $4 \mathrm{D}$ ).

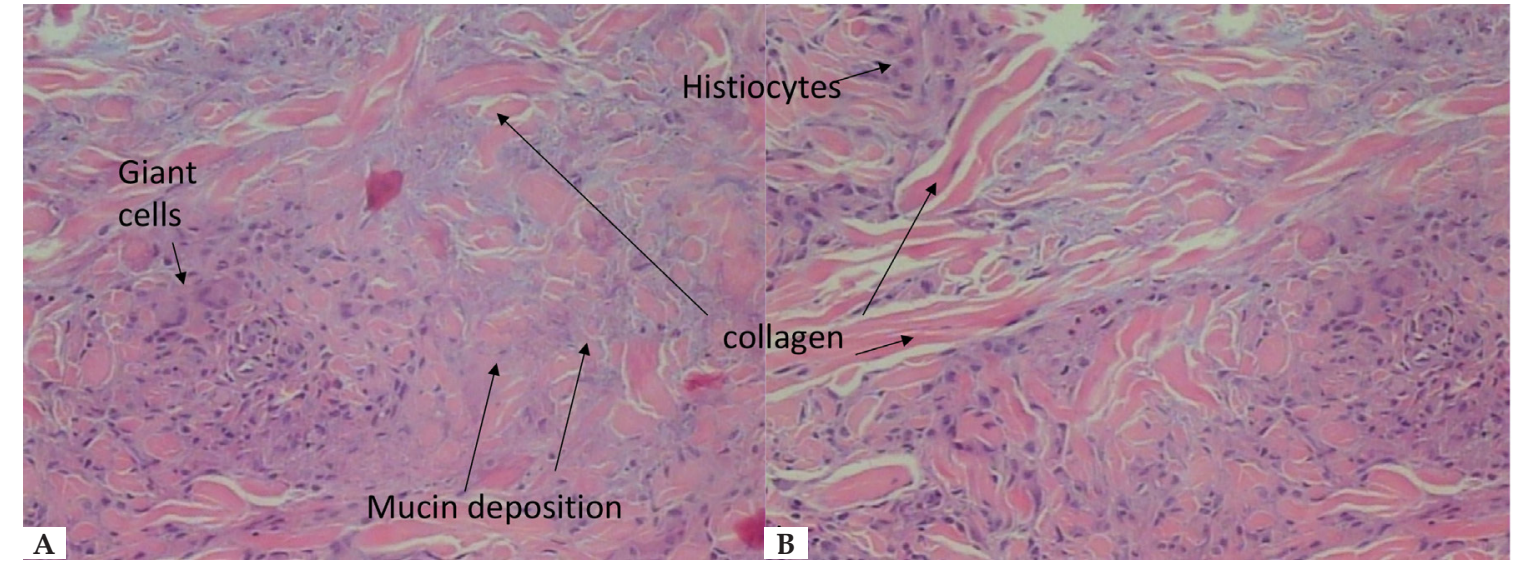

Figure 2: Light microscopy. A - basophilic mucin deposition, histiocytes and multinucleated giant cells (Hematoxylin \& eosin, x200). B - disorganized collagen bundles (Hematoxylin \& eosin, $x 200)$
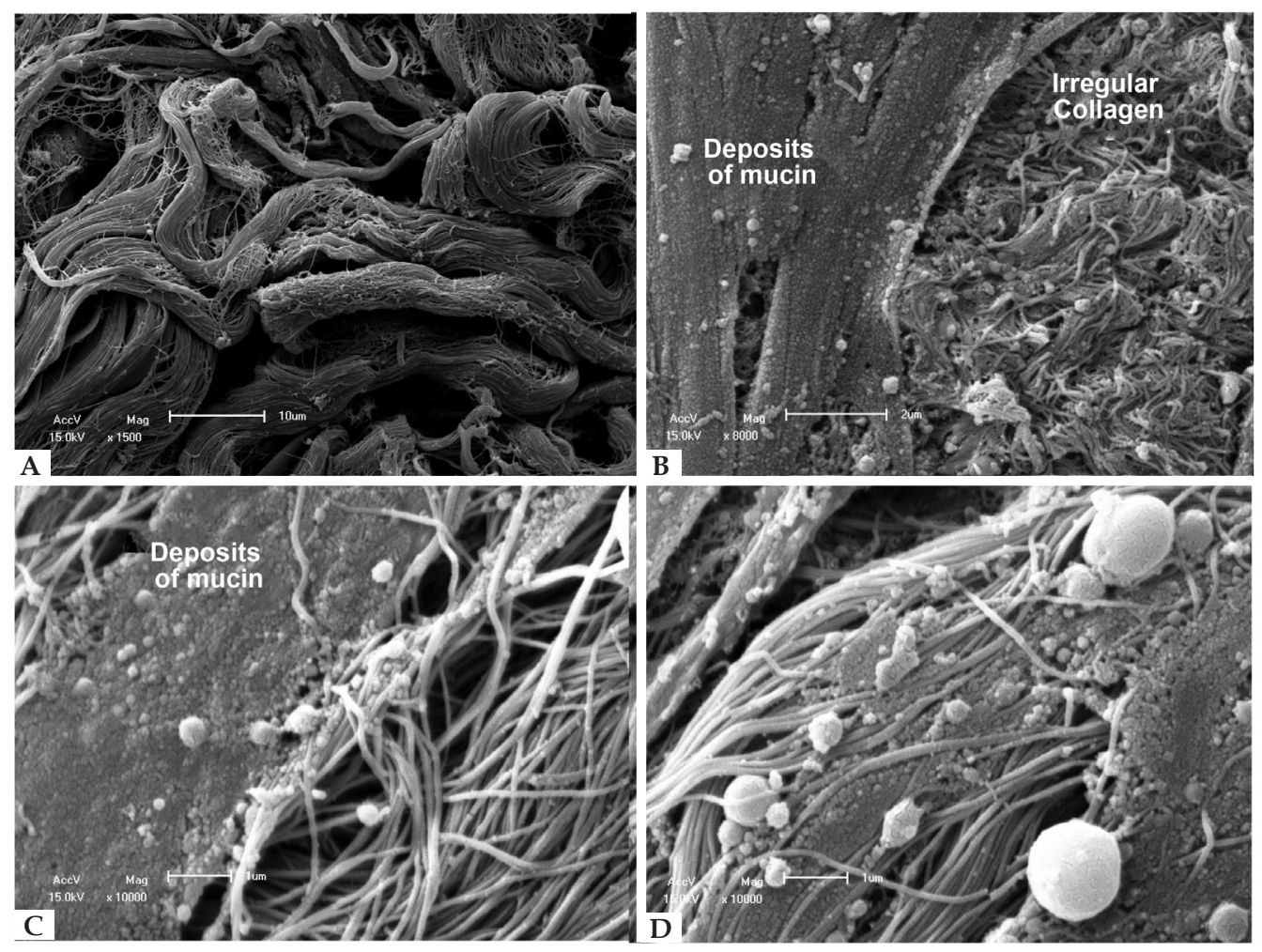

Figure 3: Scanning electron microscopy. A - normal collagen bundles in the lesion's border (x1,500). B - granular deposition of mucin and collagen fibers without bundle formation $(x 8,000)$. C - detail of granular mucin deposition $(x 10,000)$. D - detail of the compaction of the collagen by granular mucin deposition with two inflammatory lymphocytes $(x 10,000)$ 

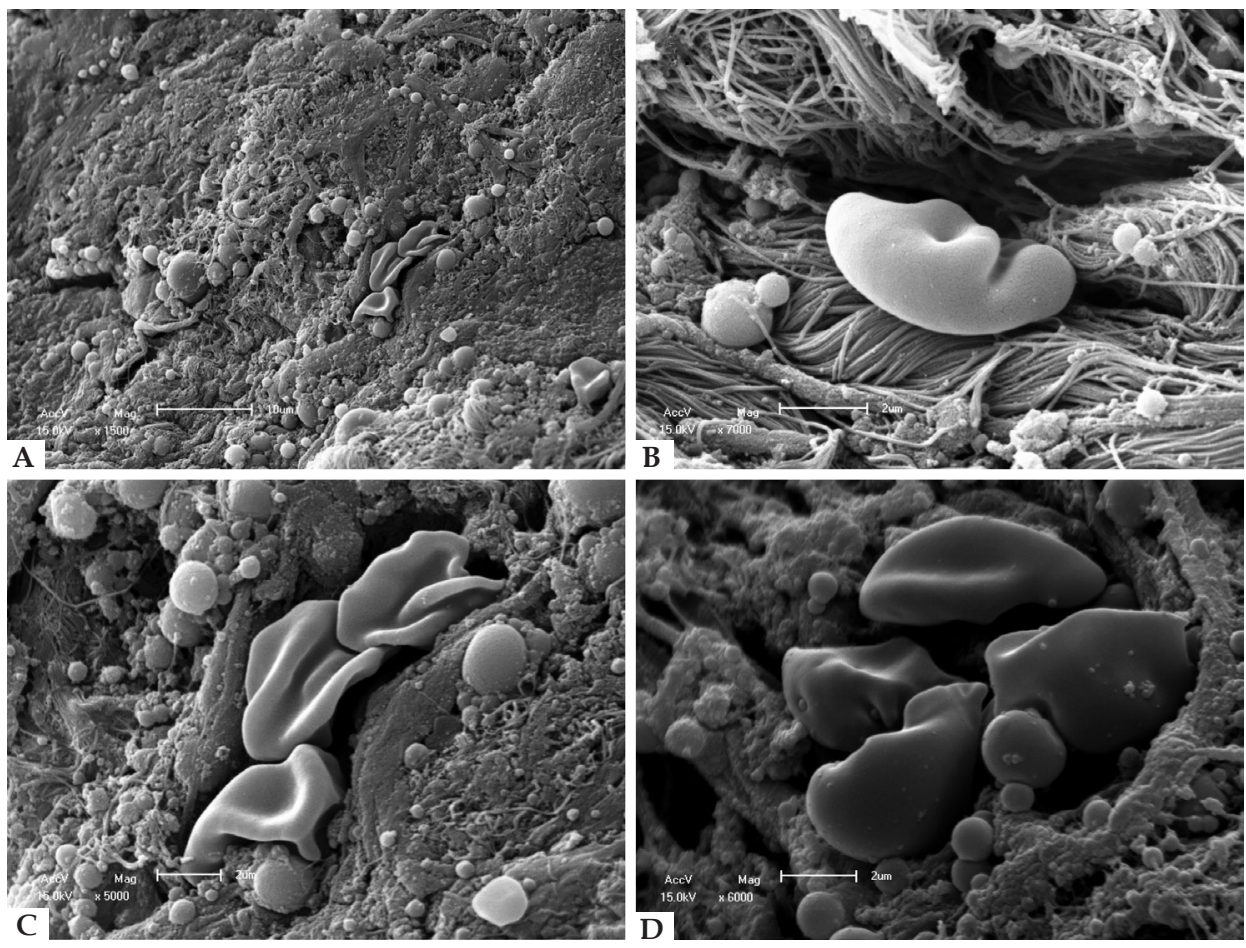

Figure 4: Scanning electron microscopy. A - Strong compaction of dermal collagen. $(x 1,500)$; B - isolated histiocyte with a lymphocyte to the left $(x 7,000)$; C - detail of an area with significant compaction of collagen, with palisading histiocytes $(x 5,000) ;$ D - grouped histiocytes $(x 6,000)$

\section{DISCUSSION}

The only publications on ultrastructural analysis of GA used transmission electron microscopy. These studies reported degeneration of elastic fibers, under phagocytic stimulation by macrophages and giant cells. ${ }^{9,10}$ Elastic fibers and collagen around the granulomas are within normal limits. ${ }^{10}$ The normally well-defined collagen bundles had disintegrated, and the regular parallel arrangement of the single fibrils within the bundles was lost.

The fibrils were swollen, cross-striated and degenerate into a granular and amorphous material. ${ }^{10}$ Histiocytes were predominant; monocytes, giant epithelioid cells and fibroblasts were also found.

\section{REFERENCES}

1. Davids JR, Kolman BH, Billman GF, Krous HF.. Subcutaneous granuloma annulare: recognition and treatment. J Pediatr Orthop. 1993;13:582-6.

2. Muhlbauer JE. Granuloma annulare. J Am Acad Dermatol. 1980;3:217-30

3. Felner El, Steinberg JB, Weinberg AG. Subcutaneous granuloma annulare: a review of 47 cases. Pediatrics. 1997;100:965-7.

4. Cyr PR. Diagnosis and management of granuloma annulare. Am Fam Physician. 2006; 74:1729-34.

5. Gamo Villegas R, Sopena Barona J, Guerra Tapia A, Vergara Sanchez A, Rodríguez Peralto JL, Iglesias Dlez L. Pustular generalized perforating granuloma annulare. Br J Dermatol. 2003;149:866-8.
Granuloma annulare observed in scanning electron microscopy has not been reported in the medical literature.

Therefore, we conclude that the findings of the scanning electron microscopy overlap with the findings of optical microscopy, allowing three-dimensional iconographic documentation of this well-known dermatosis. The reported collagen "degeneration" in light microscopy is probably due to the tight compaction of collagen because of mucin deposition, as seen with SEM, corresponding to the disorganized collagen fibers in previous reports using transmission electron microscopy. $\square$

6. Fang KS, Lawry M, Haas A. Papules on the hands. Granuloma annulare. Arch Dermatol. 2001;137:1647-52.

7. Lever WF, Schaumberg-Lever G. Histopathology of the skin. 7th ed. Philadelphia: JB Lippincott, 1990. p.257-260.

8. Hanna WM, Moreno-Merlo F, Andrighetti L. Granuloma Annulare: An Elastic Tissue Disease? Case Report and Literature Review. Ultrastruct Pathol. 1999;23:33-8.

9. Wolff $\mathrm{HH}$, Maciejewski W. The Ultrastructure of Granuloma Annulare. Arch Dermatol Res. 1977;259:225-34

10. Friedman-Birnbaum R, Ludatscher RM. Comparative Ultrastructural Study of Generalized and Localized Granuloma Annulare. Am J Dermatopathol. 1986;8:302-8.

\footnotetext{
Mariani Magnus de Andrade
} ORCID 0000-0003-4412-9757

Approval of the final version of the manuscript, Design and planning of the study, Preparation and writing of the manuscript, Collecting, analysis and interpretation of data, Critical review of the literature, Critical review of the manuscript

Pedro da Rocha Andrade Neto $\quad$ (iD) ORCID 0000-0002-5632-2346

Statistical analysis, Approval of the final version of the manuscript, Design and planning of the study, Preparation and writing of the manuscript, Collecting, analysis and interpretation of data, Critical review of the literature, Critical review of the manuscript

Approval of the final version of the manuscript, Design and planning of the study, Preparation and writing of the manuscript, Critical review of the literature, Critical review of the manuscript

How to cite this article: Almeida HL Jr, Bicca EB, Andrade MM, Andrade Neto PR. Scanning electron microscopy of granuloma annulare. An Bras Dermatol. 2018;93(5):740-2. 